\title{
Kinderradiologische Fortbildung - thorakale Bildgebung bei Kindern und Jugendlichen, Online-Fortbildung am 19. und 20.03.2021
}

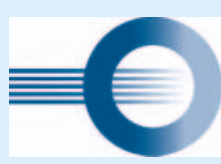

AG Pädiatrische Radiologie

in der Deutschen Röntgengesellschaft

Die AG Pädiatrische Radiologie in der Deutschen Röntgengesellschaft lädt Sie herzlich zur Kinderradiologischen Fortbildung am 19. und 20. März 2021 ein. Unter der wissenschaftlichen Leitung von PD Dr. Friederike Körber und Dr. Martin Stenzel steht die thorakale Bildgebung bei Kindern und Jugendlichen im Mittelpunkt.

Die Online-Fortbildung spannt den thematischen Bogen von den Grundlagen und angeborenen Fehlbildungen sowie den Beson- derheiten (extremer) Frühgeburten über die Onkologie und Infektionen bis hin zur Traumatologie.

Weitere Informationen zum Programm und zur Anmeldung:

www.drgakademie.de > Veranstaltungskalender 